\title{
Encountering Others in Overseas Study Tours: An Examination of Educational Potentials
}

\author{
Tomomi Naka
}

\begin{abstract}
This article examines the learning outcomes of overseas study tours. With the rapid intensification of globalization, many universities and colleges have shown an interest in supporting students to extend their cross-cultural understanding and communication skills for working with people from diverse cultural backgrounds. Study tours can provide such support. However, previous studies suggest several concerns regarding such tours, including possibilities of reinforcing stereotypes and simplistically glorifying globalization, and also causing unequal and harmful relationships between the visitors and the local population. A case study of the 2014 North American Study Tour sponsored by Tottori University suggests that such concerns do not necessarily hold true. Rather, students perceived that they improved their skills and levels of confidence, cross-cultural understanding, and communication skills by working with others in diverse cultural settings.
\end{abstract}

Index Terms-Cross-cultural understanding, globalization, international education, study tours.

\section{INTRODUCTION}

In many disciplines of the social sciences and humanities, it is becoming increasingly necessary to establish stronger connections between academic skills and perspectives gained in higher education with broader social contexts and concerns. For example, in anthropology, which is my area of specialization, the publication of a book in July 2014 titled Kokyo Jinruigaku (Public Anthropology) led to several open discussion forums for exploring the possibilities of the practical application of anthropology [1]. This trend is surely not limited to anthropology, and there is an increasing need for academia to engage in broader social problems. Following this trend, this article examines some of the ways in which overseas study tours can encourage students to make connections between their academic learning in higher education with broader and more complex social problems and concerns. More specifically, I argue that overseas study tours can encourage students to critically examine their pre-existing assumptions and to face complex sociocultural challenges and phenomena.

This article is based on a case study of the 2014 North American Study Tour sponsored by Tottori University, Japan. The data came from questionnaires, interviews, and written accounts by students who participated in this tour. Before this case is examined in detail, the following sections will provide a brief history of overseas study tours, social contexts in Japan, and concerns raised by the literature on such tours.

Manuscript received March 29, 2015; revised June 29, 2015.

T. Naka is with the Department of Regional Culture, Tottori University, Tottori, Japan (e-mail: nakatomo@ @rs.tottori-u.ac.jp).

\section{OVERSEAS STUdy TOURS}

\section{A. Brief History and Social Contexts}

Colleges and universities, along with many other institutions such as non-governmental organizations (NGOs) and private companies, currently offer diverse types of international programs. "Overseas study tours" are a type of study abroad program that usually lasts for 1 to 2 weeks, in which the participants visit one or several countries; there are many other programs that last longer. Study abroad programs typically last a semester or a full academic year. Language training programs generally run for 3 or more weeks.

Long, Yemi, Purdy, and Nakano argue that the history of study tours can be traced back to the Grand Tour, which began during the 17th century in Europe. Young and usually wealthy men traveled abroad to countries such as France and Italy to learn about their culture, language, and social conventions, including etiquette and customs [2], [3]. The Grand Tour lasted much longer than many contemporary study abroad programs, but it had a similar goal in that it intended to provide students with "first-hand" experiences of other societies.

In time, study tours became available to a much wider group of people. Long, Yemi, Purdy, and Nakano state that in the case of the United States, the rise of the American economy after World War II contributed to the increase in the number of study tours. Along with the growth of international business, more people became aware of the importance of international understanding. This led universities and other institutions to offer international study tours [2]. Funding and institutional support became available to some students, which made it possible for less wealthy students to take part in these tours.

In the case of Japan, NGOs played an important role at the beginning of overseas study tours in the 1980s [4]. In order to publicize their overseas work, many NGOs organized tours that introduced their supporters to the countries that these NGOs were working in. Gradually, universities and colleges also began to offer similar tours. NGOs and their staff, who already had experience with such tours, provided assistance to some of these programs. Similar to the United States, the growing Japanese economy in the 1980s encouraged the expansion of such tours. The financial burden became less severe than before, and the increasing interactions between Japan and other countries through business transactions led many people to recognize the importance of international understanding and cross-cultural communication.

Since the mid-2000s, overseas study tours and other international programs have received further governmental 
and popular attention. Slow economic growth, along with what is often referred to as an "inward tendency" among young Japanese people, has recently caused concern among Japanese business leaders and the government regarding Japan's future. This has led the Ministry of Education, Culture, Sports and Science and Technology to launch the Project for Promotion of Global Human Resource Development (hereafter, GHRD project), which aims to encourage universities to educate young people to become global-minded personnel who can successfully contribute to the Japanese society [5]. With competitive funding provided under this project, many universities have intensified their efforts to promote international education. Special focus has been placed on the development of students' international communication skills (English and other languages) and cross-cultural understanding. The number of overseas study tours and other international programs has been increased, along with many other domestic programs (such as the introduction of courses taught in English), to promote students' international awareness and language skills.

\section{B. Educational Potentials and Challenges of Overseas Study Tours}

Scholars suggest that overseas study tours offer various potential educational benefits. Referring to Bruner's 2005 article, Riggan, Gwak, Lesnick, Jackson, and Olitsky claim that such tours are a type of "enlightened tourism," which let students directly experience different parts of the world and broaden their views [6], [7]. However, the specific types of benefits and the degree of such benefits are the focus of scholarly discussion. One reason for such debates is that it is difficult to make equivalent comparisons because the contents of study tours and the participants are diverse. For example, the majors, years in college, and previous international experiences of student participants can vary greatly even within the programs. This has made it difficult to decipher the specific benefits that study tours can provide. Generally, however, studies tend to posit that students who participate in study tours enhance their knowledge of global geography, the customs and history of these places, and their ability to navigate in unfamiliar cultural settings [8], [9].

The present literature suggests two major concerns. The first concern is that overseas study tours reinforce rather than reduce stereotypes [7]. As in the case of casual tourists, the brevity of study tours may make it difficult for tour participants to learn new things. Critics worry that the study tours cannot provide enough learning opportunities for students to challenge their pre-existing assumptions.

In the case of study tours sponsored by the GHRD project, there are other related concerns. Yoshida argues that students who were encouraged to participate in overseas study tours under the GHRD project may end up failing to critically examine globalization. Because the meaning of "global-minded personnel" is not well defined, and travel to other countries is almost always viewed positively under the GHRD project, students who receive the benefits of visits abroad may not ponder on the economic and social challenges caused by rapid globalization [10]. Yoshida worries that such uncritical views of globalization lead students to value only the ability to maneuver in foreign countries and possess just enough proficiency of the local languages. Okada expresses a similar concern: he claims that study tours, particularly those held in conjunction with the GHRD project, may cause students to be naïve and simple-minded proponents of globalization and to neglect the importance of the ability to consider local and regional contexts and resources [11].

The second major concern is about the relationships between tour participants and the communities and people of the host country. The participants and members of the host country are often socioeconomically unequal. Considering that they do not possess enough local knowledge, inappropriate behavior by tour participants and miscommunication between the participants and the members of the host country can have grave consequences [12], [13]. Like tourists, participants in study tours leave the host countries after some time. However, the locals remain where they are and frequently bear the consequences of the actions of the tour participants. Participants' sincerity, interests, and economic revenues can bring positive outcomes; however, the negative outcomes can outweigh the positive ones.

Despite the educational potential of these tours, concerns about overseas study tours, thus, have to do with their failure to challenge stereotypes and pre-existing assumptions, including uncritical views of globalization, and unequal and harmful relationships between tour participants and locals. Through a case study of a study tour, the following section examines students' perception of their learning experiences of study tours and also focuses on the concerns and challenges mentioned here.

\section{CASE STUdy: 2014 NORTH AMERICAN STUdy TOUR}

The 2014 North American Study Tour was one of the seven one-credit courses titled Overseas Fieldwork at the Faculty of Regional Sciences of Tottori University, Japan. Although similar tours were held for several years before 2014, this was the first year in which these courses were incorporated into the curriculum. Partial financial support for these courses comes from funding for the GHRD project. The particular tour discussed here was organized under a theme of multicultural North America, focusing on Asian (in particular, Japanese and Chinese) immigrants' history and experiences. From February 27 to March 11, 2014, eight students visited universities, research and community centers, and museums in Davis and San Francisco (California, USA) and Vancouver (British Columbia, Canada). Students attended lectures and interacted mostly with local people of Asian ethnic backgrounds, and also with those of other ethnic backgrounds, and of different ages.

Similar to many other short-term study tours, participants of this tour (eight students, three are male and five are female) cannot be easily classified as one group. One is regional education major and the rest of the students belong to the Department of Regional Culture. Two students are in the first year, the rest of the students were second year students (Table I).

Generally speaking, the students had limited overseas experience. None of them had been to the United States or 
Canada, and four of them had never been abroad (Table II). Those who had been abroad had traveled to Singapore, Malaysia, the Philippines, and Taiwan. One student was from Taiwan.

TABLE I: TOUR PARTICIPANTS

\begin{tabular}{lll}
\multicolumn{2}{c}{ TABLE I: TOUR PARTICIPANTS } \\
\hline \hline \multirow{2}{*}{ Major of students } & $\begin{array}{l}\text { Number of male } \\
\text { students }\end{array}$ & $\begin{array}{l}\text { Number of female } \\
\text { students }\end{array}$ \\
\hline Regional Culture & $2 *$ & 5 \\
Regional Education & 1 & 0 \\
\hline \hline
\end{tabular}

*First year students

TABLE II: STUDENTS' OVERSEAS EXPERIENCES PRIOR TO THE TOUR

\begin{tabular}{ll}
\hline \hline Overseas visits & Number of students \\
\hline None & 4 \\
Once & 2 \\
More than Once & 2 \\
\hline \hline
\end{tabular}

The analysis is based on the information collected in the form of questionnaires, individual interviews, and journals and essays written by the students. The questionnaires comprised ten questions, which asked students to identify their skills, level of confidence, and other abilities related to the aim of the GHRD project (see Table III). For example, questions included to what extent students felt comfortable working in international settings, to what degree they were aware of international events and important world problems, and the degree to which they could communicate and collaborate with people of diverse cultural backgrounds. The participants were asked to check the most appropriate levels of their skills and situations. The questionnaires and interviews were conducted before and after the trip to explore how students' perceptions about themselves changed because of the tour. For confidentiality, the students' names in this article are pseudonyms.

\section{RESULT}

Comparisons between pre- and post-tour questionnaire answers suggest that the majority of students considered that their abilities and levels of confidence had improved in the following areas: skills and confidence to work comfortably in international settings; confidence in adapting and competing in globalized settings; willingness to work with others of diverse cultural backgrounds and in global situations; ability to understand new cultures, customs, and perspectives; and ability to converse with others of diverse backgrounds, using appropriate linguistic and other communication skills and tools (Table III).

Because of the small number of participants, the questionnaire analysis is limited. However, individual interviews, journals, and other writing accounts provide additional information that aids in examining students' experiences related to the tour. This approach also helps consider the diversity of the students, while evaluating the overall learning experiences of the tour.

Reflecting on their tour experiences, all the students commented that they learned a lot about cultural diversity and the history of Japanese and Chinese Americans. During the tour, the students had opportunities not only to listen to scholarly lectures and to visit exhibits, but also to personally talk with diverse Japanese and Chinese Americans and Canadians. Through such encounters, students could learn about the challenges and difficulties related to these Americans' and Canadians' experiences, including the discrimination they faced and their ordeal in Japanese internment camps during World War II. Furthermore, the students learned how they value their cultural heritage.

TABLE III: COMPARISON OF STUDENT PERCEPTIONS OF ONE'S LEVELS OF SKILLS AND CONFIDENCE

\begin{tabular}{|c|c|}
\hline Areas of skills & $\begin{array}{l}\text { Number of students } \\
\text { indicate } \\
\text { improvements after } \\
\text { the tour } \\
\text { (out of } 6 \text { students*) }\end{array}$ \\
\hline $\begin{array}{l}\text { Skills and confidence to work comfortably in } \\
\text { international settings }\end{array}$ & 4 \\
\hline $\begin{array}{l}\text { Confidence to adapt and compete in globalized } \\
\text { settings }\end{array}$ & 4 \\
\hline $\begin{array}{l}\text { Clear vision of one's future goals and efforts to } \\
\text { achieve them }\end{array}$ & 2 \\
\hline $\begin{array}{l}\text { Self-management skills to work in harsh and } \\
\text { difficult environment }\end{array}$ & 2 \\
\hline $\begin{array}{l}\text { Awareness of major international events, trends, } \\
\text { and world problems }\end{array}$ & 2 \\
\hline $\begin{array}{l}\text { Knowledge of Japanese history, society, and } \\
\text { culture and ability to explain these }\end{array}$ & 2 \\
\hline $\begin{array}{l}\text { Awareness and willingness to work toward } \\
\text { solving global problems and challenges }\end{array}$ & 2 \\
\hline $\begin{array}{l}\text { Ability to understand culture, customs, and } \\
\text { perspectives different from one's own background }\end{array}$ & 3 \\
\hline $\begin{array}{l}\text { Ability and willingness to work with diverse } \\
\text { group of people to produce something new }\end{array}$ & 2 \\
\hline $\begin{array}{l}\text { Ability to discuss with others of diverse } \\
\text { backgrounds, using appropriate linguistic and } \\
\text { other communication skills and tools }\end{array}$ & 3 \\
\hline
\end{tabular}

Hearing about these experiences left a strong impression on the students. All of them said that they learned a lot about the history of Asian and other ethnic minorities in the United States and Canada, and that they now recognized how little they knew prior to the tour. The students had heard about discrimination against ethnic minorities and efforts to promote cultural diversity in class (most of them had taken an introductory course on American society and culture) and on other occasions. However, listening personally to stories from Japanese Americans and Canadians brought the topic much closer to the students and helped them consider the effects of racial and ethnic discrimination on people's lives.

Yuki's account is an illustrative example. Yuki mentioned that one of the most memorable experiences on the tour was her conversation with older Japanese and Chinese Americans. Through a course she had taken, she knew that considerable efforts were made by the United States government to promote the awareness of cultural and ethnic diversity, but she had not thought deeply about its significance. Yet, having heard these people speak about the difficult experience of living as children of immigrants before and after the war, she felt that she could understand the value of such efforts much better than before. This realization led her to think about the importance of listening to the stories and experiences of 
others. She said that having grown up in Japan and as a member of the ethnic majority in Japan, she could not fully understand their perspectives unless she tried to listen to others as well. Having thought about the importance of accepting cultural and ethnic diversity, Yuki now also wonders how foreign residents in Japan might feel about living in Japan.

The generational diversity among Japanese and Chinese Americans and Canadians also brought insight to many students as they had only a vague image of the lives of ethnic and cultural minorities in the United States and Canada. Some were a little perplexed to learn that a young, third-generation Japanese, who, despite his active involvement in a Japanese cultural center, does not speak Japanese. This led the students to notice that Japanese language fluency or physical appearance alone may not accurately reflect one's cultural and ethnic identity. Prior to the tour, most of the students took their cultural and ethnic identities for granted because of their mother tongue, their physical appearance, and the location of their birth. However, the tour experiences gave students the opportunity to ponder on what it means to be Japanese, Chinese, or Taiwanese and to realize that cultural identity and ethnicity are more complex than previously understood.

Several others said that they were impressed to discover how important cultural and social ties were to the Japanese or the Chinese communities. Through their visit to a Japanese temple and cultural centers, the students learned that events related to these cultures continue to be celebrated in the United States and Canada. In addition, conversations with Japanese Americans and Canadians suggested that these persons often maintain social ties to the regions from where they or their ancestors came through annual social events and personal networks. Erika, for example, said that she was impressed by such ongoing networks, and that she was thinking about how she might find one herself when she works or studies abroad. For a Taiwanese student, Mei-ling, this trip made the question of ethnic identity an even more pressing one to consider. Having lived in Japan for more than four years, and with many friends and social ties to Japan, Mei-ling said that she sometimes wondered who she was and where her "home" was. The stories of Japanese and Chinese Americans and Canadians resonated in her mind, especially as she thinks about life after completing her time at the university.

As with Erika and Mei-ling, the tour also led other students to ponder on their personal lives. Yuki is another example. She said that she previously thought that she wanted to be an English teacher because she liked English. However, since the tour, she now wants to take a job that will allow her to deliver the cultural information that she has gathered. To explain this change in career goals, she recounted her conversation with one of the Japanese Americans at a workshop on writing personal family histories. When Yuki learned from an old woman about her difficult experiences, Yuki wondered if it was difficult for the old woman to write about these experiences. But the old woman explained to Yuki that she liked writing about these because not all memories were painful, and writing helped her share her experiences with others. Impressed by this woman, Yuki wants to be like her, by telling stories and providing information from which others may benefit.

These accounts by the students suggest some of their thinking behind the questionnaire answers. The stories of the Japanese Americans and Canadians, along with other people encountered on the tour, provided the students with a new and deeper awareness of the importance of respecting diverse cultural backgrounds. Furthermore, by interacting with these people in English, as well as in Japanese, the students had first-hand opportunities to exchange viewpoints, despite the differences in historical and cultural experiences.

These students' accounts also help in examining some of the criticism and skepticism related to the learning potential of study tours. One criticism of overseas study tours mentioned above is that such tours reinforce rather than dispel stereotypes and pre-existing assumptions [7]. However, the comments by the students suggest that this is not necessarily the case. As exemplified in the deeper understanding that Yuki gained of life in an ethnically and culturally diverse society, the tour led students to re-examine the value of cultural and ethnic diversity, and what it means to be American, Canadian, Japanese, or Chinese.

Another related concern discussed above was that study tours foster uncritical views of globalization and a disregard for the value of local knowledge and contexts. Stories about immigrants and Asian Americans and Canadians were not necessarily all rosy success stories of fulfilled dreams. Some Asian Americans and Canadians certainly took advantage of economic and other opportunities that might not be available in their home communities. However, the students' interactions with these individuals, as well as the opportunity they had to view exhibits and hear lectures, led them to learn that hardship and continuous effort were behind such success. As Mei-ling's account suggests, some students start to ponder an increasingly complex sense of self, including their own ethnic identity, as the process of globalization advances and the movement of people and goods intensifies. Although the specific focus of this tour case should be considered, it suggests that study tours do not inherently promote simplistic and uncritical views of globalization.

Furthermore, as Yuki's question about foreign residents in Japan suggests, some students brought their experiences back home and explored them further. Takumi is another example. In talking with a Japanese Canadian couple at a Buddhist temple, he learned that many Japanese Canadians in Vancouver are from Wakayama prefecture, where his hometown is located. Surprised by this, he undertook a mini-research trip to a village in Wakayama, where many immigrants came from, and recounted what he discovered about local resources then and now in his final essay. These comments indicate that some students also try to relate what they learned abroad to the local and national situation.

Another concern about overseas study tours and the related GHRD project has to do with the relationships between tour participants and the communities and people that host them. Those who are skeptical about such study tours point out that the tours may create sustained unequal power relationships between the visitors and the local people. The transient nature of the visitors cannot be completely erased, but their lack of familiarity with the locale they are visiting and their often 
limited knowledge of these communities do not necessarily lead to harmful relationships. In the case study discussed here, the students were frequently amazed at the insights offered by the American and Canadian people they encountered. As Yuki's comment suggests, many students came to see the limited knowledge and perspectives they possessed. For the students, those encountered on the trip were experts, although they might not have had the same educational qualifications as the students or the teachers. In addition, when visited communities are interested in the focus of a tour, then repeat visits by students may indicate their sustained interest in these communities and can be positively perceived. On this tour, for instance, some staff members at the research centers and local people remembered the previous tour visit. Their memory of that earlier visit not only helped both the hosts and the visitors know what to expect but also led to the hosts' providing additional resources and assistance as they started to see that this study tour was not a one-time event, but that the institution has a continued educational interest in the community.

\section{CONCLUSION}

The analysis of this case study through questionnaires, interviews, and written accounts by the students suggests that the students expanded their understanding, critically examined complex cultural and social phenomena, and learned the importance of working with various people by listening to their stories and perspectives. The levels of confidence and skills of the students who participated in this tour vary, but the majority of them perceived some growth in these areas. Comments in interviews and written accounts suggest that the tour experiences not only deepened their knowledge but also led them to bring their newly acquired perspectives back to their lives in Japan. Furthermore, there is little indication that the concerns raised by the literature, such as the danger of strengthening stereotypes and unequal power relationships between the visitors and the visited, actually materialized.

This case study, thus, suggests that students can achieve good learning outcomes through overseas study tours. Of course, it is necessary to carefully consider the diverse nature of these tours and of the participants in order to apply these results to other similar tours. However, qualitative analyses such as the one used in this case study can help us illuminate some of the ways in which study tours can expand their educational potential. For example, a comparison with other cases may improve written reflections and other methods for documenting students' learning during and after the tours.

As an example of the emerging field of public anthropology mentioned at the beginning of this article suggests, there has been an increased interest in emphasizing the connections between the social sciences and humanities at higher education with the broader social concerns and problems. Further research on study tours and careful application of the findings can provide insights into how to design better short-term study tours, which can also contribute to encouraging students to consider the links between their learning and a complex and increasingly globalized society.

\section{REFERENCES}

[1] S. Yamashita, "Kokyo jinruigaku," Public Anthropology, Tokyo, Japan: Tokyo Digaku Shuppan Kai, 2014.

[2] S. O. Long, A. S. Yemi, R. W. Purdy, and K. Nakano, "Deepening learning and inspiring rigor: Bridging academic and experiential learning using a host country approach to a study tour," Journal of Studies in International Education, vol. 14 no. 1, pp. $89-111 \mathrm{~m}$ February 2010.

[3] W. Hoffa, "A history of U.S. study abroad: 1965 to present," The Interdisciplinary Journal of Study Abroad, 2010.

[4] I, Fujiyama, "Social impact of overseas experiential learning: Service-learning in university education and international cooperation activities," Ritsumeikan Koto Kyoiku Kenkyu, vol. 11, pp. 117-130, 2011.

[5] Project for Promotion of Global Human Resource Development [Online]. http://www.mext.go.jp/english/highered/1326713.htm

[6] E. Bruner, Culture on Tour: Ethnographies of Travel, Chicago: University of Chicago Press, 2005.

[7] J. Riggan, S. Gwak, J. Lesnick, K. Jackson, and S. Olitsky, "Meta-travel: A critical inquiry into a China study tour," Frontiers: The Interdisciplinary Journal of Study Abroad, vol. 21, p. 238, 2011.

[8] M. Kurt, N. H. Olitsky, and P. Geis, "Assessing global awareness over short-term study abroad sequence: A factor analysis," Frontiers: The Interdisciplinary Journal of Study Abroad, vol. 23, pp. 22-41, 2013.

[9] H. C. Ruddock, and De. S. Turner, "Developing cultural sensitivity: Nursing students' experiences of a study abroad programme," Journal of Advanced Nursing, vol. 59, no. 4, pp. 361-369, 2007.

[10] A. Yoshida, "Global human resource development and university education in Japan: From the perspective of localism discussion among actors", Kyoikugaku Kenkyu, vol. 2, pp. 164-175, 2014.

[11] T. Okada, "Consideration of global human resources from a local perspective," Kokyo Kukan, Autumn, pp. 13-15, 2013.

[12] N. M. Doerr, "Do 'global citizens' need the parochial cultural other? Discourse of immersion in study abroad and learning-by-doing," Compare: A Journal of Comparative and International Education, vol 43, no. 2, pp. 224-243, 2013.

[13] M. M. Camacho, M. M. "Power and privilege: community service learning in Tijuana," Michigan Journal of Community Service Learning, vol. 10, no. 3, pp. 31-42, 2004.

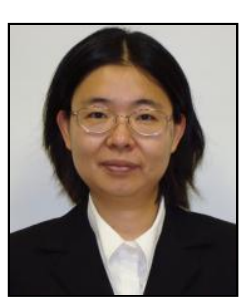

Tomomi Naka is a lecturer in the Department of Regional Culture at Tottori University, Japan. She received a $\mathrm{PhD}$ (Anthropology) at the University of Iowa, Iowa City, USA, in 2009. Her research interests include cross-cultural educational experiences, religion, economic activities, and the representation of cultural and religious minorities.

For the past 12 years, she has worked in three countries (USA, Bangladesh, and Japan) as a university and college instructor. While working with a diversity of students, she has conducted research on their learning experiences from the viewpoint of cultural and ethnic identities and language ideologies, and she has published several articles on this topic. She has been also working with groups of Mennonites in the United States and elsewhere for the past ten years, with a special emphasis on spending and occupational pursuits.

Dr. Naka is a member of the American Anthropological Association and the Japanese Society of Cultural Anthropology. She has received many awards and fellowships, including the Young Center Graduate Summer Fellow at the Young Center for Anabaptist and Pietist Studies at Elizabethtown College, Elizabethtown, Pennsylvania, USA. 